\title{
Phosphorylated tyrosine-containing proteins in primary lung cancer correlates with proliferation and prognosis (DOI)
}

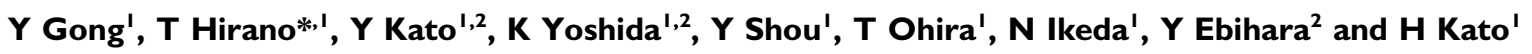 \\ 'Department of Surgery, Tokyo Medical University, 6-7 Nishishinjuko, Shinjuku-ku, Tokyo 160-0023, Japan.; 'Department of Pathology, Tokyo Medical \\ University, 6-7 Nishishinjuko, Shinjuku-ku, Tokyo 160-0023, Japan
}

To determine the usefulness of tyrosine phosphorylation in evaluating biological characteristics, we attempted to evaluate the relationship between the amount of phosphorylated tyrosine-containing proteins and clinicopathological factors, cell proliferation and outcome in non-small cell lung cancer. To evaluate phosphorylated tyrosine-containing proteins we used 96 surgically resected materials of non-small cell lung cancer and normal peripheral lung, while immunohistochemical evaluation was performed. Cell proliferating ability was evaluated using the labelling index of proliferating cell nuclear antigen-positive nuclear staining cells. There were statistically significant differences between the expression levels of phosphorylated tyrosinecontaining proteins of normal and cancerous tissues $(P<0.000 \mathrm{I})$. Evaluations based on clinicopathological factors apart from histopathological differentiation, showed no statistically significant differences of phosphorylated tyrosine-containing proteins expression. However, phosphorylated tyrosine-containing proteins correlated with cell proliferation activity evaluated $\left(P_{\text {(Low, }}\right.$ High) $<0.000$ I; $P_{(\text {Low, Int })}<0.000$ I; $P_{(\text {Int }, \text { High })}<0.000$ I). Furthermore, non-small cell lung cancer cases with high expression and intermediate expression of phosphorylated tyrosine-containing proteins had a significantly shorter disease-free postoperative survival than those with low expression of phosphorylated tyrosine-containing proteins using log-rank analysis ( $P_{\text {(Low, Int) }}$ $<0.0028 ; P_{(\text {Low, High) }}=0.0002$ ). Furthermore, phosphorylated tyrosine-containing proteins expression level statistically contributed to disease-free survival in Cox's proportional hazard model. Therefore, phosphorylated tyrosine-containing proteins in non-small cell lung cancer tissues seem to reflect its biological malignancy, and this evaluation may be valuable for constructing the most appropriate therapeutic strategy.

British Journal of Cancer (2002) 86, 1893-1898. doi:I0.1038/sj.bjc.6600327 www.bjcancer.com

(c) 2002 Cancer Research UK

Keywords: phosphorylated tyrosine-containing proteins; cell proliferating activity; histopathological differentiation; poor prognosis; lung cancer

Primary lung cancer is one of the most malignant solid tumours. In spite of current improvements in combined therapy, its incidence and mortality rates are still increasing in Japan. Since the clinical courses of lung cancer patients are extremely varied, and an understanding of the individual characteristics of the tumour could be important, and the evaluation of useful biomarker may be valuable for constructing the most appropriate therapeutic strategy.

Recently, extensive studies have been performed to identify oncogenes that encode tyrosine-protein kinase in human cancer cells (Kiyokawa et al, 1994; Peng and Cartwright, 1995; Goodman et al, 2001) and certain evidence suggests that oncogenes of the tyrosine kinase-type are involved in the tumorigenesis (Scrimgeour et al, 1997; Hung and Elliott, 2001) and immortalisation (McCormack et al, 1997; Vogt et al, 1989) of various types of human cancers. Aberrant expression of epidermal growth factor (EGF) receptors and HER2/neu proto-oncogene have been reported in primary lung cancer (Dazzi et al, 1989; Schneider et al, 1989; Kern et al, 1990). In general, it was proved that aberrant expression of oncogenes or EGF-receptors was associated with Tyr-phosphorylation (Reynolds et al, 1989; Takeshima et al, 1991) and that pTyr-

*Correspondence: T Hirano; E-mail: m-hirano@guitar.ocn.ne.jp. Received 3 December 200 I; revised 26 March 2002; accepted 27 March 2002 proteins are deeply related to cell cycle regulation (Yaacov et al, 1991). Furthermore, increase of pTyr-proteins might correlate with the morphological transformation of tumour cells (Hamaguchi et al, 1988). Clinically, it was reported that overexpression of pTyrproteins $100-130 \mathrm{kDa}$ in molecular weight might predict shortened survival of lung cancer patients (Nishimura et al, 1996). Thus, a close relationship between tyrosine phosphorylation and biological characteristics of the malignant tumours has been speculated upon. However, there are few reports using clinical materials concerning pTyr-proteins in cancer cells.

In this context, we attempted to clinicopathologically evaluate the relationship between tyrosine phosphorylation and tumour characteristics using surgically resected materials of non-small cell lung cancer (NSCLC), and to discuss the clinical significance of pTyr-proteins in NSCLC.

\section{MATERIALS AND METHODS}

\section{Preparation of surgically-resected tumours and normal peripheral lung tissues}

Clinical materials were obtained from 96 patients with NSCLC, resected at the Department of Surgery, Tokyo Medical University from October 1997 to May 1999. All specimens were collected from cancerous tissues and normal peripheral lung tissues located far 
from the cancerous lesion in the same lobe. The cancerous tissue materials $(10 \times 10 \times 3 \mathrm{~mm}$ in size $)$ were collected from relatively near the margin of the primary lesions to avoid both necrosis and scar tissue. After tissue collection, inhibition of disphosphorylated kinases is immediately necessary. Therefore, tissue-materials were incubated in $1 \mathrm{~mm}$ orthovanadate solution at $200 \mathrm{mmHg}$ for $5 \mathrm{~min}$ (Akimoto et al, 1998). After inhibition of disphosphorylated kinases, materials were acetone-fixed and paraffin-embedded (Sato et al, 1986). Sample preparation (the inhibition of disphosphorylated kinases) was started within $30 \mathrm{~min}$ after the surgical resection.

The 96 cases were diagnosed pathologically as adenocarcinoma (62 cases), squamous cell carcinoma (31 cases), and large cell carcinoma (three cases). Furthermore, adenocarcinoma and squamous cell carcinoma was histopathologically classified as well, moderately and poorly differentiated. Tumours were classified according to the histological subgroups recommended by the World Health Organization (Travis et al, 1999) and staged by the tumour-nodal involvement-metastasis (TNM) system according to the UICC TNM classification, fifth edition (Sobin and Wittekind, 1997).

\section{Immunohistochemical staining}

The surgically resected specimens were stained immunohistochemically using an avidin-biotin peroxidase complex (ABC) method (Akimoto et al, 1998). We used a mouse monoclonal antibody clone 4G10 (VEC, NY, USA) (Druker et al, 1989; Cohen et al, 1990; Kanakura et al, 1991) for the detection of pTyr-proteins, and anti-proliferating nuclear antigen (PCNA) mouse monoclonal antibody PC10 (DAKO, Copenhagen, Denmark) for the detection of proliferating activity of tumour cells. We evaluated pTyrproteins and PCNA using consecutive slices of tissues.

\section{Expression levels of the tyrosine phosphorylation and cell proliferation}

Epithelial cells with cytoplasmic staining were judged as the pTyrproteins-rich cells when pTyr-proteins were evaluated. Cases were classified into three groups according to the frequency of positive cells: high expression (High), more than 68\% (mean \pm standard deviation (s.d)) positive cells; intermediate expression (Int), 9$68 \%$ (mean \pm s.d.) positive cells; and low expression (Low), less than $8 \%$ (mean \pm s.d.) positive cells.

Cell proliferating ability was evaluated using the PCNA labelling index of positive nuclear staining cells.

\section{Western blot and immunodetection of pTyr-proteins}

Disphosphorylated kinases-inhibited materials of human lung cancer and normal peripheral lung were subjected to $7.5 \%$ SDSpolyacrylamide gel electrophoresis as described previously (Laemmli, 1970; Weiner et al, 1990; Kanakura et al, 1991), and proteins were transferred electrophoretically to Immobilon PVDF membrane (Millipore). PTyr-proteins on the membrane were immunodetected with monoclonal antibody (clone 4G10) and an enhanced chemiluminescence (ECL) western detection reagents kit (Amersham, Little Chalfont, Buckinghamshire, UK) (Kaufmann et al, 1987; Hoffman and Jump, 1989).

\section{Statistical analysis}

Statistical analysis of the data was performed by Student's $t$-test. The Kaplan-Meier method was used to estimate the disease-free survival probability for each group. The log rank test was used to compare survival curves. Differences were considered statistically significant when the $P$-value was less than 0.05 . Also, the influence of variables on postoperative disease-free survival was assessed using Cox's proportional hazard model. The following variables were used in the Cox regression: $\mathrm{t}$-factor, $\mathrm{n}$-factor, lymphatic invasion, vascular invasion and pTyr-protein expression levels. A value of less than 0.05 was considered to indicate a statistically significant difference.

\section{RESULTS}

\section{pTyr-proteins expression}

The features of immunohistochemical staining are shown in Figure 1. Cells with pTyr-proteins were detected in 71 cases $(74.0 \%)$ out

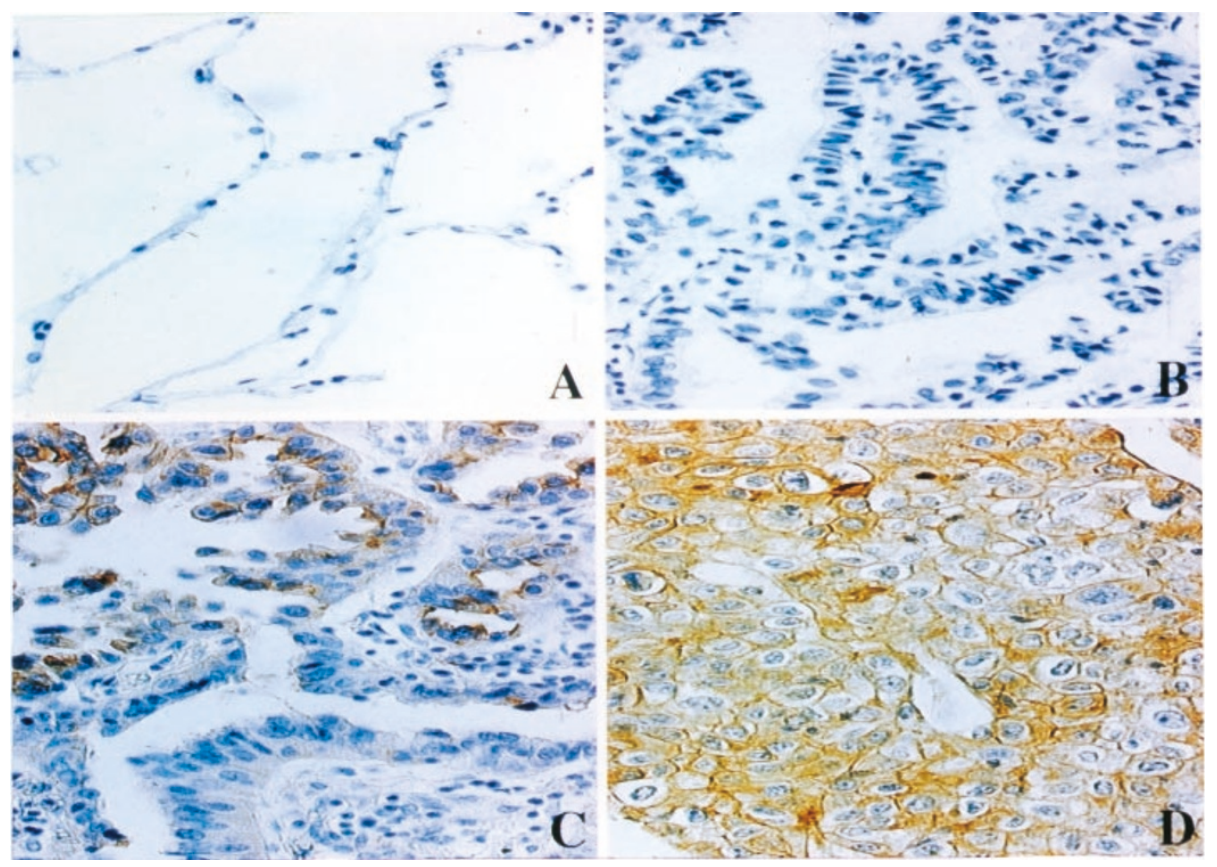

Figure I Immunohistochemical staining of phosphorylated tyrosine-containing proteins (pTyr-proteins) (A) Normal peripheral lung tissue; B - D: nonsmall cell lung cancer. (B) Low expression, (C) intermediate expression, (D) high expression. 
of the 96 NSCLC cases, but with various expression levels. On the other hand, only $13(13.6 \%)$ normal peripheral lung tissues showed positive cells. Furthermore, 10 of these 13 cases possessed less than $20 \%$ positive cells.

Also, we detected pTyr-proteins in Western-blot analysis (Figure 2). Cancerous tissues expressed pTyr-proteins showing various molecular weight $(120,85,75,45$, and $30 \mathrm{kDa})$ in the cancerous tissues. On the contrary, a few pTyr-proteins were expressed in the normal peripheral lung.

Figure 3 shows the expression levels of pTyr-proteins in the normal and malignant tissues. There was a statistically significant difference in pTyr-protein expression between normal and cancerous tissues $(P<0.0001)$.

\section{Tyrosine phosphorylation and clinicopathological features}

Table 1 shows the relationship between the expression levels of pTyr-proteins and clinicopathological factors. No statistically significant differences were found in any clinicopathological factors. However, there was a statistically significant difference among different degrees of histopathological differentiation of NSCLC $(P<0.0001$ between well and moderate differentiation,

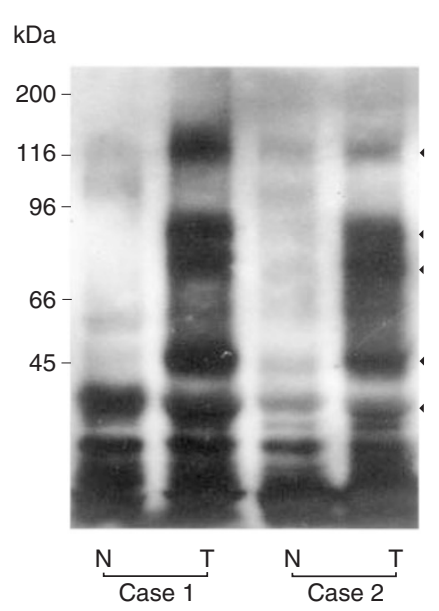

Figure 2 Detection of pTyr-proteins in human tissues of peripheral lung and lung cancer using Western blot analysis. We detected pTyr-proteins with various molecular weights. Arrowheads showed pTyr-proteins with approximately $120,85,75,45$ and $30 \mathrm{kDa}$ in molecular weight. $\mathrm{N}$ : normal peripheral tissue; T: cancerous tissue. Case I: Adenocarcinoma; Case 2: Squamous cell carcinoma.

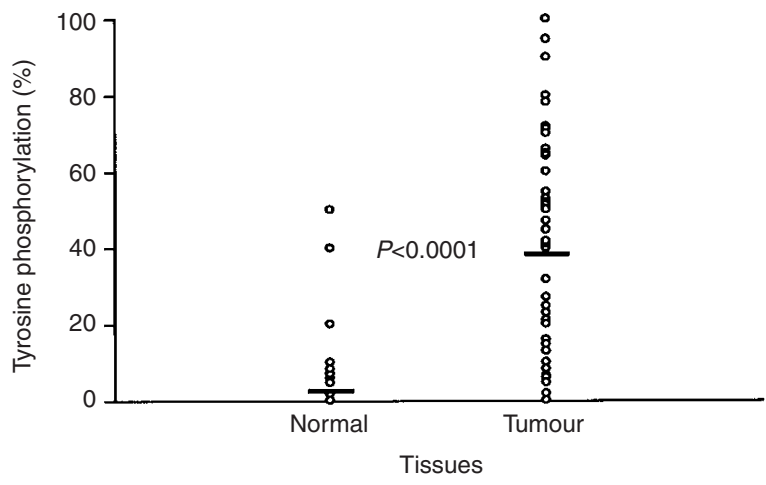

Figure 3 The relationship of pTyr between normal (mean \pm s.d.: $2.26 \pm 8.03$ ) and tumour (mean \pm s.d.: $38.13 \pm 30.15$ ) tissues was showed. The Student's $t$-test was used to estimate the tyrosine phosphorylation levels.
Table I Relationship between expression of pTyr-proteins and clinicopathological factors in the 96 patients with NSCLC

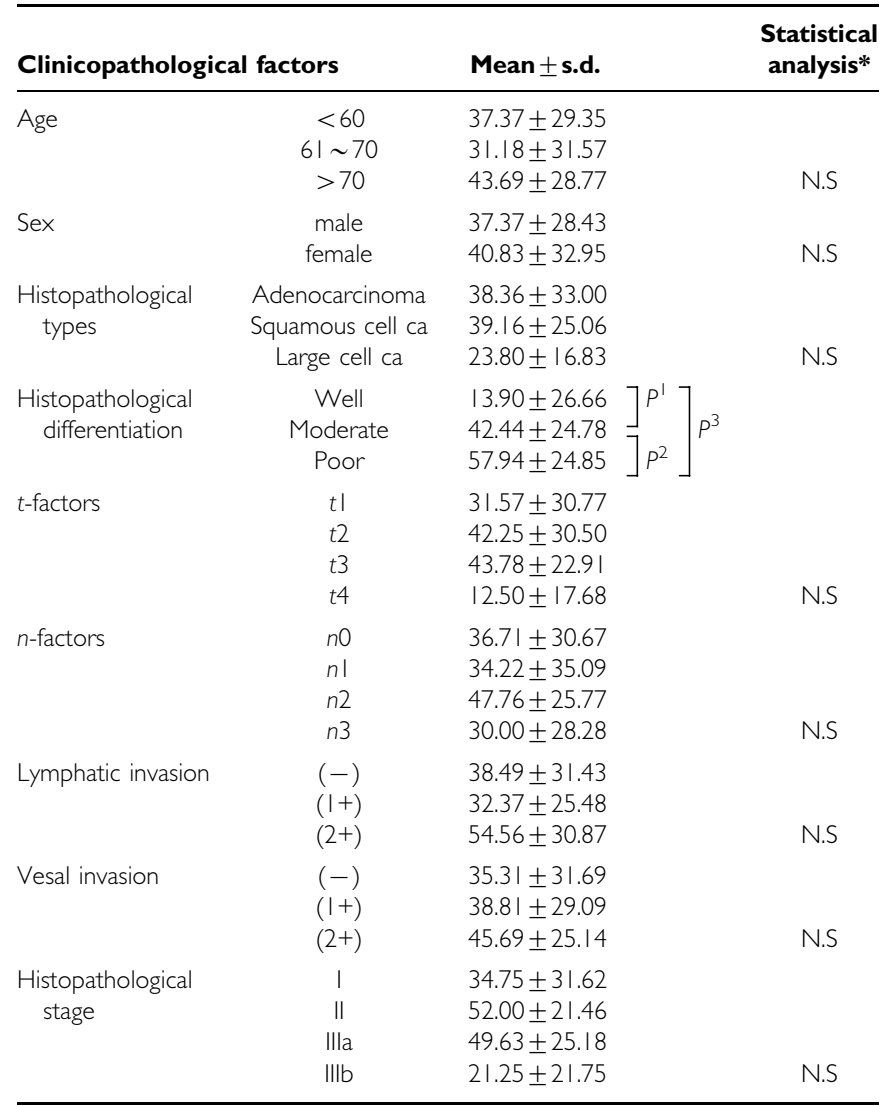

*Statistical analysis was performed using Student's t-test. N.S=not significant. $P^{1}<0.000$ I; $P^{2}=0.0367 ; P^{3}<0.0001$.

$P<0.0001$ between well and poor differentiation and $P=0.0367$ between moderate and poor differentiation).

\section{The relationship between expression levels of pTyr-proteins and cell proliferation}

Figure 4 shows the relationship between the expression levels of pTyr-proteins and cell proliferating ability using the PCNA labelling index in NSCLC tissues. There was a statistically significant

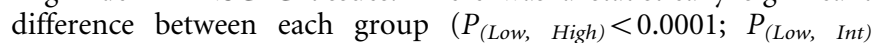
$\left.<0.0001 ; P_{(\text {Int }, \text { High })}<0.0001\right)$.

\section{The expression levels of pTyr-proteins and the disease-free survival}

Postoperative follow-up-periods in all cases were more than 25 months in this study. Figure 5 shows the disease-free survival curves for each expression levels of pTyr-proteins. There was a statistically significant difference between cases with low expression and intermediate expression $(P=0.0028)$, and cases with low expression and high expression $(P=0.0002)$ (Figure 5a). Only in stage I cases was there a statistically significant difference between cases with low expression and intermediate expression $(P=0.0188)$, and cases with low expression and high expression $(P=0.0006)$ (Figure 5b).

\section{The contribution to postoperative disease-free survivals}

All variables ( $\mathrm{t}$-factor, $\mathrm{n}$-factor, lymphatic invasion, vascular invasion and pTyr-protein expression levels) were included in a 
multivariate analysis by Cox proportional hazards model. In the stepwise analysis, $\mathrm{n}$-factor, vascular invasion and pTyr-proteins expression level revealed statistical significance. PTyr-proteins expression levels were found to be an independent prognostic indicator as well as $\mathrm{n}$-factor and vascular invasion (Table $2 \mathrm{~A}$ ). In the investigation of only stage I-cases pTyr-protein expression levels were significantly related to disease-free survival. In the stepwise analysis no other variable revealed statistical significance (Table 2B).

\section{DISCUSSION}

Primary lung cancer is an aggressive and highly malignant tumour frequently having an extremely miserable outcome. Even in lung cancers diagnosed as pathological stage I, approximately $30 \%$ relapse mainly due to distant metastasis. At present pathological staging based on TNM classification is the most reliable method to estimate patient prognosis, but the results are not satisfactory. Biological markers reflecting tumour characteristics might enhance evaluation of patient prognosis.

It is now known that carcinogenesis and tumour progression are related to the accumulation of mutations of oncogenes and tumour supressor genes (Fearon and Vogelstein, 1990; Sozzi et al, 1992; Sundaresan et al, 1992; Hirano et al, 1994). Nearly half of known oncogenes encode tyrosine kinases and are distributed throughout whole human cells. Yet, there are a few reports concerning the relationship between the expression of pTyr-proteins and human cancer (Hunter and Sefton, 1980; Shibamoto et al, 1994). According to a previous investigation using immunoprecipitation, the overexpression of tyrosine-phosphorylated 100-130 kDa proteins correlated with poor prognosis in lung cancer cases (Nishimura et al, 1996; Imaizumi et al, 1997). We also detected these $100-$

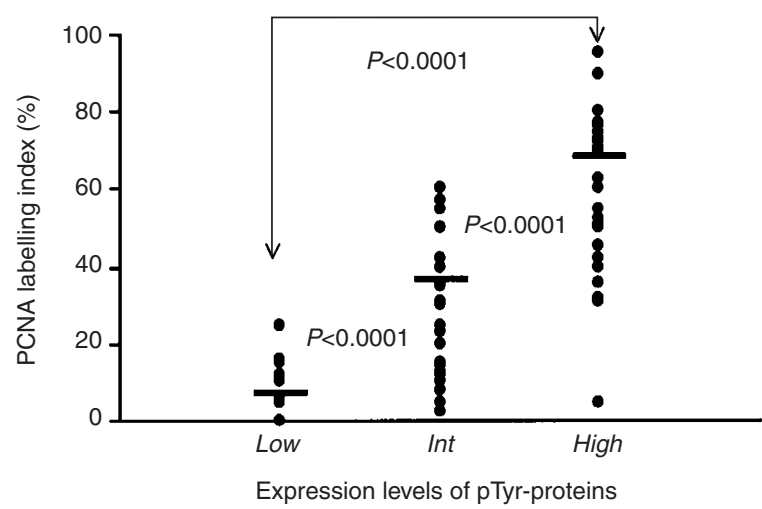

Figure 4 The relationship between pTyr expression levels and PCNA (mean \pm s.d.: $p-\operatorname{Tyr}($ Low), $7.08 \pm 8.79$; p-Tyr(Int), 36.74 \pm 19.31; p-Tyr(High) $68.57 \pm 11.20$ ) was shown. The statistical analysis was performed using Student's t-test.
$130 \mathrm{kDa}$ pTyr-proteins by Western blot analysis of surgically resected materials of both normal and cancerous tissues of the lung (Figure 2). However, the high expression of these proteins is not always associated with high malignancy of lung cancer. Also, pTyr-proteins with more varied molecular weights, including lower molecular weights, were detected in malignant tissues. There is a possibility that the pTyr-proteins with relatively lower molecular weight may belong to the other kinds of tyrosine kinase including src family and its related proteins. Therefore, we attempted to immunohistohemically evaluate all pTyr-proteins in surgically resected NSCLC tissues as well as in normal peripheral lung tissues from the same lobe, but distant from the primary lesion.

In only 13 out of $96(13.6 \%)$ normal peripheral lung tissues were pTyr-proteins detected, even at a low expression level. We
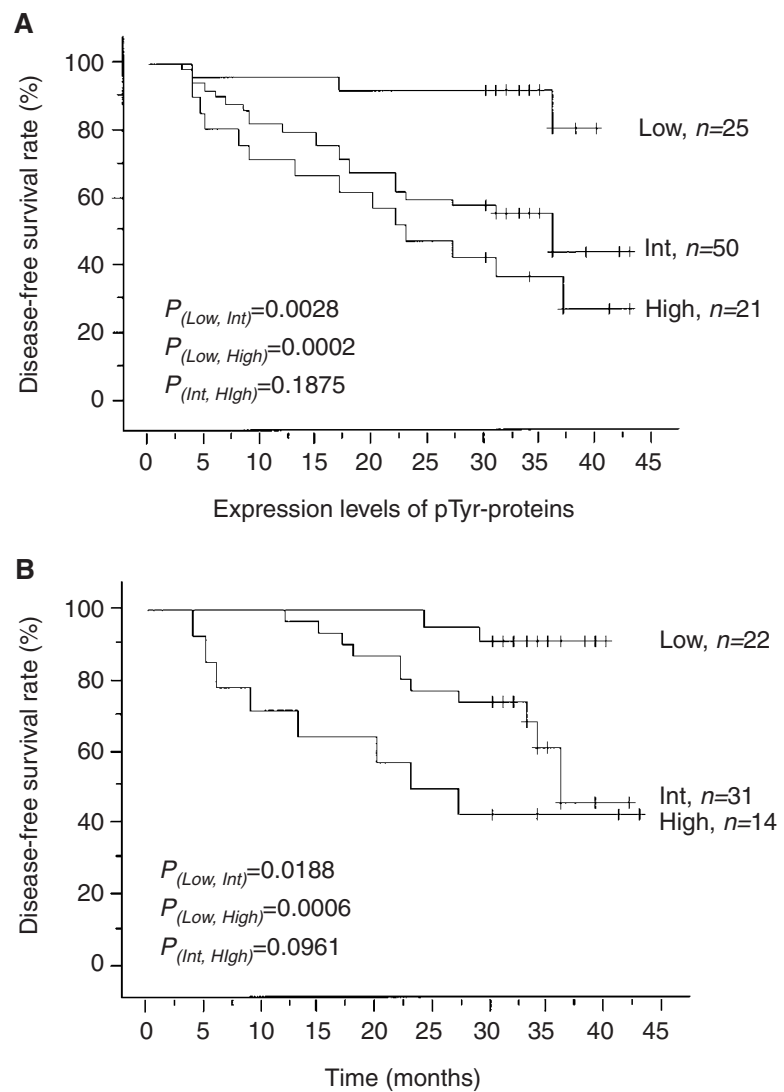

Figure 5 Actuarial curves for disease-free survival of patients with NSCLC according to the levels of pTyr-proteins. (A) All patients with NSCL; (B) Stage l-patients with NSCLC. The Kaplan-Meier method was used to estimate the survival distribution for each group. The log rank test was used to evaluate the equality of the survival curves.

Table 2 Multivariate analysis of postoperative survival with the Cox proportional hazards model

\begin{tabular}{|c|c|c|c|c|c|c|c|}
\hline Variable & DF & Estimate & Std err & $\chi^{2}$ & Prob $\chi^{2}$ & Hazard ratio & $95 \% \mathrm{Cl}$ \\
\hline \multicolumn{8}{|c|}{ (A) All patients with NSCLC } \\
\hline pTyr \% & । & 0.55749 & 0.25278 & 4.86377 & 0.02743 & 1.74628 & $1.0640 \mid-2.86605$ \\
\hline ctor & 1 & 37 & 0.1 & | 3.87437 & 0 & & 1.352 \\
\hline Vesal invasion & I & 1.10366 & 0.23191 & 22.64869 & 0.00000 & 3.01519 & $1.91388-4.75023$ \\
\hline \multicolumn{8}{|c|}{ (B) Stage I-patients with NSCLC } \\
\hline pTyr \% & 1 & 0.89056 & 0.33362 & 7.12576 & 0.0076 & 2.4 & $1.26704-4.68535$ \\
\hline Lymphatic invasion & 1 & 0.54059 & 0.38895 & 1.93175 & 0.16457 & 1.71701 & $0.80113-3.67998$ \\
\hline Vesal invasion & । & 0.43819 & 0.33874 & 1.6733 & 0.19582 & 1.54989 & $0.79793-3.01051$ \\
\hline
\end{tabular}

DF: degree of freedom; Std err: standard error; Prob: probability; Cl: confidence interval. 
have to emphasise that protein phosphorylation is essential for maintaining normal functions in normal cells, even if generally the expression levels are extremely low compared with the expression level in malignant neoplastic tissues. Indeed, we also detected very low levels of pTyr-proteins even in ciliated bronchial epithelium as well as alveolar cells (data not shown).

In lung-cancerous tissues various expression levels of pTyrproteins were detected in 71 out of $96(74.0 \%)$ lung cancer materials. Furthermore, as the degree of histopathological differentiation of cancerous tissues became poorer, the expression levels of pTyrproteins increased. These results support the concept that overexpression of pTyr-proteins may be associated with malignant transformation and progression of lung cancer. We also obtained data indicating a positive relationship between elevations of pTyr-proteins and increased cell proliferation ability. Most growth factor receptors, including epidermal growth factor (EGF) receptor, platelet derived growth factor (PDGF) receptor and HER2/neu possesses tyrosine-kinase activity and have been reported to be closely associated with cell proliferation (Kokai et al, 1988; Rahimi et al, 1998; Tanaka et al, 1998; Liu et al, 2000). In this study, we evaluated cell proliferation immunohistochemically in terms of the labelling index of PCNA using the consecutive slice of the same materials used for evaluation of pTyr-proteins. A closely significant relationship between pTyr-proteins and PCNA was recognised (Figure 4). Therefore, our data supported that the mechanisms of the elevation of pTyr-proteins are probably related to cell growth though several pathways.

Also, a statistically significant difference in the expression levels of pTyr-proteins according to the level of histopathological differentiation was recognised. At present, histopathological differentiation is diagnosed by experienced pathologists mainly based on histopathological and cellular structures. In general, poorly differentiated tumours show large differences in cellular shapes and sizes and loss of histological structures. Even though histopathological differentiation is one of the most important factors reflecting tumor malignancy, the criteria of histopathological differentiation are largely subjective. $\alpha$ - and $\beta$-catenins are essential for tight cell-cell adhesion through e-cadherin, because the cadherin-catenine complex combines with actin filaments. The deletion of these molecules causes tumour cells not only to lose the function of cell-cell adhesion but to change cellular formation (Shimoyama et al, 1992). In addition, it is already known that the phosphorylation of $\beta$-catenins induce dysfunction of e-cadherin (Matsuyoshi et al, 1992; Hamaguchi et al, 1993). Therefore, there is a possibility that phosphorylation may be related to morphological alterations.

\section{REFERENCES}

Akimoto S, Ochiai A, Inomata M, Hirohashi S (1998) Expression of cadherin-catenin cell adhesion molecules, phosphorylated tyrosine residues and growth factor receptor-tyrosine kinases in gastric cancers. Jpn J Cancer Res 89: $829-836$

Cohen B, Yoakim M, Helen PW, Roberts TM, Schaffhausen BS (1990) Tyrosine phosphorylation is a signal for the traffiching of pp85, an $85-\mathrm{Kda}$ phosphorylated polypeptide associated with phosphatidylinositol kinase activity. Proc Natl Acad Sci USA 87: 4458-4462

Dazzi H, Hasleton PS, Thatcher N, Barnes DM, Wilkes S, Swindell R, Lawson RAM (1989) Expression of epidermal growth factor receptor (EGF-R) in non-small cell lung cancer. Use of archival tissue and correlation of EGF-R with histology, tumour size, node status and survival. Br J Cancer 59: $746-749$

Druker BJ, Mamon HJ, Roberts TM (1989) Oncogenes, growth factors, and signal transduction. New Eng J Med 16: 1383-1391

Fearon ER, Vogelstein B (1990) A genetic model for colorectal tumorigenesis. Cell 61: $759-767$
The clinical impact of this study may be to clarify the significant relationship between the expression of pTyr-proteins and survival probability after surgery. Our findings indicate that overexpression of pTyr-proteins is associated with poor disease-free survival in spite of the absence of correlation with clinicopathological factors. At the same time, Cox regression multivariate analysis indicated that vascular invasion, $\mathrm{n}$-factor and $\mathrm{pTyr}$-proteins were unfavourable factors. Furthermore, this analysis showed pTyr-proteins overexpression to be only one significant prognostic-factor among stage I NCSLC cases. In this context, there is a high possibility that pTyr-protein overexpression must be deeply associated with malignant biological characteristics, and that several mechanisms of phosphorylation in cancerous cells are responsible for poor prognosis in the patients with NSCLC. As new therapeutic strategies, adjuvant therapy seems to be needed for stage I-cases with pTyrproteins overexpression. In addition, world-wide clinical trials using a tyrosine kinase inhibitor seems to be obtaining favourable results. When this kind of medicine will be used clinically in the near future, the evaluation of expression levels of pTyr-proteins might be valuable for the prediction of effectiveness of tyrosine kinase inhibitors.

This study suggests that tyrosine-phosphorylation is related to histopathological differentiation, cell proliferating ability and poor prognosis. According to previous reports, a few independent survival markers (Bcl-2 for longer survival, and mutant-p53 for shorter survival) were shown (Ohsaki et al, 1996; Moldvay et al, 2000). Our study did not focus on the evaluation of a specific molecule. The evaluation of pTyr-proteins reflected the expression levels and activities of various kinds of tyrosine-kinase, cell proliferation ability and cell to cell adhesion indirectly and comprehensively. In addition, pTyr-proteins expression levels were independent of pathological TNM-staging. Therefore, we conclude that evaluation of pTyr-proteins is valuable to more fully understand the biological characteristics of tumour cells, and we believe that it may be valuable for constructing the most appropriate therapeutic strategy.

\section{ACKNOWLEDGEMENTS}

The authors are indebted to Professor J Patrick Barron and T Kojima of the International Medical Communications Centre of Tokyo Medical University for his review of this manuscript.

Goodman PA, Wood CM, Vassilev A, Mao C, Uckun FM (2001) Spleen tyrosine kinase (Syk) deficiency in childhood pro-B cell acute lymphoblastic leukemia. Oncogene 20: 3969-3978

Hamaguchi M, Grandori C, Hanafusa H (1988) Phosphorylation of cellular proteins in rous sarcoma virus-infected cells: analysis by use of anti- phosphotyrosine antibodies. Molec Cell Biol 8: 3035-3042

Hamaguchi M, Matsuyoshi N, Ohnishi Y, Gotoh B, Takeichi M, Nagai Y (1993) $\mathrm{p} 60^{\mathrm{v}-\mathrm{src}}$ causes tyrosine phosphorylation and inactivation of the N-cadherin-catenin cell adhesion system. EMBO J 12: 307-314

Hirano T, Franzen B, Kato H, Ebihara Y, Auer G (1994) Genesis of squamous cell lung carcinoma-sequential changes of proliferation, DNA ploidy, and p53 expression. Am J Pathol 144: 296-302

Hoffman WL, Jump AA (1989) Inhibition of the Streptavidin-Biotin Interaction by Milk. Anal Biochem 181: 318-320

Hung W, Elliott B (2001) Co-operative effect c-Src tyrosine kinase and stat 3 in activation of hepatocyte growth factor expression in mammary carcinoma cells. J Biol Chem 276: 12395-12403 
Hunter T, Sefton BM (1980) Transforming gene product of Rous sarcoma virus phosphorylates tyrosine. Proc Natl Acad Sci USA 77: 1311-1315

Imaizumi M, Nishimura M, Takeuchi S, Murase M, Hamaguchi M (1997) Role of tyrosine phosphorylation of cellular proteins, especially EGF receptor and p125FAK in human lung cancer cells. Lung Cancer 17: 69-84

Kanakura Y, Druker B, Dicarlo J, Cannistra SA, Griffin JD (1991) Phorbol 12myristate 13-acetate inhibits granulocyte-macrophage colony stimulating factor-induced protein tyrosine phosphorylation in a human factor-dependent hematopoietic cell line. J Biol Chem 266: 490-495

Kaufmann SH, Ewing CM, Shaper JH (1987) Anal Biochem 161: 89-95

Kern JA, Schwartz DA, Nordberg JE, Weiner DB, Greene MI, Torney L, Robinson RA (1990) P185 ${ }^{\text {neu }}$ expression in human lung adenocarcinomas predicts shortened survival. Cancer Res 50: 5184-5191

Kiyokawa E, Takai S, Tanaka M, Iwase T, Suzuki M, Xiang YY, Naito Y, Yamada K, Sugimura H, Kino I (1994) Overexpression of ERK, an EPH family receptor protein tyrosine kinase, in various human Tumors. Cancer Res 54: 3645-3650

Kokai Y, Dobashi K, Weiner DB, Myrrs JN, Nowell PC, Greene MI (1988) Phosphorylation process induced by epidermal growth factor alters the oncogenic and cellular neu (NGL) gene products. Proc Natl Acad Sci USA 85: $5389-5393$

Laemmli UK (1970) Cleavage of structural proteins during the assembly of the head of bacteriophage T4. Nature 227: 680-685

Liu PS, Wang PY, Michaely P, Zhu MF, Anderson RGW (2000) Presence of oxidized cholesterol in caveolae uncouples active platelet-derived growth factor receptors from tyrosine kinase substrates. J Biol Chem 275: $31648-31654$

Matsuyoshi N, Hamaguchi M, Taniguchi S, Nagafuchi A, Tsukita S, Takeichi M (1992) Cadherin-mediated cell-cell adhesion is perturbed by v-src tyrosine phosphorylation in metastatic fibroblasts. Cell Biol 118: 703-714

McCormack SJ, Brazinski SE, Moore Jr JL, Werness BA, Goldstein DJ (1997) Activation of the focal adhesion kinase signal transduction pathway in cervical carcinoma cell lines and human genital epithelial cells immortalized with human papillomavirus type 18. Oncogene 15: 265-274

Moldvay J, Scheid P, Wild P, Nabil K, Siat J, Borrelly J, Marie B, Farre G, Labib T, Pottier G, Sesboue R, Bronner C, Vignaud JM, Martinet Y, Martinet N (2000) Predictive survival markers in patients with surgically resected non-small cell lung carcinoma. Clin Cancer Res 6: 1125-1134

Nishimura M, Machida K, Imaizumi M, Abe T, Umeda T, Takeshima E, Watanabe T, Ohnishi Y, Takagi K, Hamaguchi M (1996) Tyrosine phosphorylation of $100-130 \mathrm{kDa}$ proteins in lung cancer correlates with poor prognosis. Br J Cancer 74: 780 - 787

Ohsaki Y, Toyoshima E, Fujiuchi S, Matsui H, Hirata S, Miyokawa N, Kubo Y, Kikuchi K (1996) bcl-2 and p53 protein expression in non-small cell lung cancer: correlation with survival time. Clin Cancer Res 2: 915-920

Peng ZY, Cartwright CA (1995) Regulation of the Src tyrosine kinase and Syp tyrosine phosphatase by their cellular association. Oncogene 11: 19551962

Rahimi N, Hung W, Tremblay E, Saulnier R, Elliott B (1998) c-Src kinase activity is required for hepatocyte growth factor-induced motility and anchorage-independent growth of mammary carcinoma cells. J Biol Chem 273: $33714-33721$
Reynolds AB, Roesel DJ, Kanner SB, Parsons JT (1989) Transformationspecific tyrosine phosphorylation of a novel cellular protein in chicken cells expressing oncogenic variants of the avian cellular src Gene. Mol Cell Biol 9: $629-638$

Sato Y, Mukai K, Watanabe S, Goto M, Shimosato Y (1986) The AmeX method. A simplified technique of tissue processing and paraffin embedding with improved preservation of antigens for immunostaining. Am J Pathol 125: $431-435$

Schneider PM, Hung MC, Chiocca SM, Manning J, Zhao X, Fang K, Roth JA (1989) Differential Expression of the c-erbB2 Gene in human small Cell and Non-Small Cell Lung Cancer. Cancer Res 49: 4968-4971

Scrimgeour AG, Blakesley VA, Stannard BS, LeRoith D (1997) Mitogen-activated protein kinase and phosphatidylinositol 3-kinase pathways are not sufficient for insulin-like growth factor I-induced mitogenesis and tumorgenesis. Endocrinology 138: $2552-2558$

Shibamoto S, Hayakawa M, Takeuchi K, Hori T, Oku N, Miyazawa K, Kitamura N, Takeichi M, Ito F (1994) Tyrosine phosphorylation of $\beta$-catenin and plakoglobin enhanced by hepatocyte growth factor and epidermal growth factor in human carcinoma cells. Cell Adhes Commun 1: 295-305

Shimoyama Y, Nagafuchi A, Fujita S, Gotoh M, Takeichi M, Tsukita S, Hirohashi S (1992) Cadherin dysfunction in a human cancer cell line: possible invovement of loss of $\alpha$-catenin in reduced cell-cell adhesiveness. Cancer Res 52: $5770-5774$

Sobin LH, Wittekind Ch (eds) (1997) UICC: TNM Classification of malignant tumours. 5th edn. pp 91-100, New York: John Wiley \& Sons

Sozzi G, Miozzo M, Donghi R, Pilotti S, Cariani CT, Pastorino U, Porta GD, Pierotti MA (1992) Deletions of $17 \mathrm{p}$ and $p 53$ mutations in preneoplastic lesions of the lung. Cancer Res 52: 6079-6082

Sundaresan V, Ganly P, Hasleton P, Rudd R, Sinha G, Bleehen NM, Rabbitts P (1992) P53 and chromosome 3 abnormalities, characteristic of malignant lung tumors, are detectable In preinvasive lesions of the bronchus. Oncogene 7: 1989-1997

Takeshima E, Hamaguchi M, Watanabe T, Akiyama S, Kataoka M, Onnishi Y, Xiao H, Nagai Y, Takagi H (1991) Aberrant elevation of tyrosine-specific phosphorylation in human gastric cancer cells. Jpn J Cancer Res 82: $1428-1435$

Tanaka K, Nagayama Y, Nakano T, Takamura N, Namba H, Fukada S, Kuma K, Yamashita S, Niwa M (1998) Expression profile of receptor-type protein tyrosine kinase genes in the human thyroid. Endocrinology 139: 852-858

Travis WD, Colby TV, Corrin B, Shimosato Y, Brambilla (1999) Histological typing of lung and pleural tumours. World Health Organization (WHO) International Histological Classification of Tumours, Third Edition

Vogt M, Haggblom C, Swift S (1989) Growth factor independence and indefinite growth ('immortalization') appear simultaneously after crisis in murine myelocytes expressing v-myc. Oncogene Res 4: 19-28

Weiner DB, Nordberg J, Robinson R, Nowell PC, Gazdar A, Greene MI, Williams WV, Cohen JA, Kern JA (1990) Expression of the neu geneencoded protein $\left(\mathrm{P} 185^{\text {neu }}\right)$ in human non-small cell carcinomas of the lung. Cancer Res 50: $421-425$

Yaacov BD, Letwin K, Tannock L, Bernstein A, Pawson T (1991) A mammalian protein kinase with potential for serine/threonine and tyrosine phosphorylation is related to cell cycle regulators. EMBO J 10: $317-325$ 